\title{
Tema-tema Pengalaman Perjumpaan Antarbudaya Mahasiswa Perantauan sebagai Bahan Perancangan Psikoedukasi Keterampilan Budaya
}

\author{
Themes of Intercultural Encounter Experiences among Sojourn \\ Students as a Material for Designing Cultural Skills Psychoeducation
}

\author{
Edward Theodorus \\ Fakultas Psikologi, Universitas Sanata Dharma
}

Submitted 18 August 2020 Accepted 8 June 2021 Published 30 October 2021

\begin{abstract}
Sojourn students tend to experience culture shock when moving from their hometown to the place where they studied. Designing interventions to help them cope with the culture shock needed to be based on real life experiences. This study aimed to examine experiences of intercultural contact among sojourners who were residents of a private university's student residence in Yogyakarta. Psychology of culture shock or 'acculturation' theory was used as conceptual framework. Data were collected from 57 participants, recruited with convenience sampling method. Data were analyzed using qualitative thematic analysis approach, assisted with QDA Miner Lite software. The results showed six main themes: 1) idealism, 2) food, 3) geographical conditions, 4) language and communication skills, 5) stereotypes, and 6) social network. The themes were discussed in light of several perspectives: acculturation theory, social psychology of self-affirmation and stereotype threat, cultural marginalization, and intercultural communication skills. Implications included the need to consider the themes in designing psychoeducation programs and higher education policy.
\end{abstract}

Keywords: acculturation; intercultural relations; sojourn students

Abstrak. Mahasiswa perantauan pada umumnya mengalami gegar budaya saat berpindah dari daerah asalnya ke daerah tempat kuliah. Perancangan intervensi yang membantu mahasiswa perantauan dalam mengatasi gegar budaya perlu didasarkan pada pengalaman nyata yang relevan bagi mereka. Penelitian ini bertujuan untuk menyelidiki pengalaman perjumpaan antarbudaya mahasiswa residen asrama salah satu universitas swasta di Yogyakarta. Teori yang digunakan adalah teori akulturasi/gegar budaya. Penelitian ini menggunakan desain kualitatif, yaitu analisis tematik. Sebanyak 57 mahasiswa residen asrama berpartisipasi. Pemilihan partisipan menggunakan teknik convenience sampling. Data diperoleh dengan diskusi kelompok terarah (FGD). Data dianalisis menggunakan metode analisis tematik, dibantu dengan perangkat lunak QDA Miner Lite. Hasil penelitian menunjukkan enam tema pokok, yaitu: 1) idealisme, 2) makanan, 3) kondisi geografis, 4) pemahaman bahasa dan keterampilan komunikasi, 5) stereotip, dan 6) jejaring sosial. Perspektif psikologi akulturasi (gegar budaya), psikologi sosial afirmasi diri dan ancaman stereotip, peminggiran budaya, dan keterampilan komunikasi antarbudaya digunakan dalam membahas temuan. Implikasinya adalah perancangan psikoedukasi dan kebijakan perlu mempertimbangkan keenam tema tersebut beserta diskusi yang menyertainya.

Kata kunci: akulturasi; mahasiswa perantau; perjumpaan antarbudaya 
Mahasiswa perantauan pada umumnya mengalami gegar budaya saat berpindah dari daerah asalnya ke daerah tempat kuliah (Ward et al., 2001; Ward \& Geeraert, 2016). Gegar budaya ini berupa stres dan permasalahan emosional terkait perbedaan budaya dan gaya hidup. Mahasiswa perantauan perlu terampil menyesuaikan diri, mengatasi stres, dan mengelola emosi agar dapat hidup nyaman dan produktif selama menuntut ilmu di daerah perantauan.

Sebagian mahasiswa perantauan mengalami kesulitan dalam meningkatkan keterampilan penyesuaian budaya tersebut, sehingga membutuhkan intervensi berupa pelatihan atau psikoedukasi (Ward et al., 2001). Jika para peneliti atau praktisi ingin merancang suatu intervensi terkait proses perjumpaan antarbudaya mahasiswa perantauan, maka isi intervensi perlu didasarkan pada pengalaman nyata yang relevan bagi mahasiswa perantau (Jackson, 2015; Li et al., 2018; McKinley, 2019; Tohidian \& Quek, 2017).

Perjumpaan antarbudaya mahasiswa perantauan telah banyak diteliti dalam konteks internasional. Penelitian Shu et al. (2020) menunjukkan bahwa dukungan sosial dari teman dan institusi pendidikan merupakan prediktor signifikan terhadap penyesuaian diri mahasiswa, sedangkan dari keluarga dan orang signifikan lainnya kurang signifikan. Shu et al. tidak memperinci perbandingan negara asal mahasiswa. Penelitian Wang et al. (2012) menunjukkan bahwa kemampuan koping stres sebelum tiba di daerah tujuan dan setelah pulang dari daerah tujuan perlu dipertimbangkan. Penelitian Demes dan Geeraert (2015) memperlihatkan lima jenis perlintasan stres mahasiswa perantau seiring waktu.

Berbagai penelitian di atas mengandaikan universalitas variabel-variabel perjumpaan antarbudaya mahasiswa internasional dan membanding-bandingkan secara psikometrik berbagai sampel partisipan. Pendekatan ini termasuk pendekatan psikologi lintas budaya (Greenfield, 2000). Kelebihan pendekatan ini di antaranya objektivitas, universalitas, dan kemampuan replikasinya, sedangkan keterbatasannya adalah kurang kontekstual dan memandang budaya sebagai sesuatu yang statis (Greenfield, 2009, 2017, 2018). Untuk itu diperlukan penelitian dengan pendekatan lain, yaitu psikologi budaya (Doucerain, 2019). Pendekatan ini menyasar berbagai konstruk psikologis, termasuk konstruk perjumpaan antarbudaya, secara dinamis, kualitatif, dan kontekstual. Penelitian ini menggunakan pendekatan psikologi budaya, mendalami hanya satu sampel dalam satu konteks, yaitu mahasiswa residen asrama di suatu universitas swasta di Yogyakarta.

Penelitian-penelitian yang mendalami sampel tertentu misalnya penelitian terhadap mahasiswa Asia Timur yang berkuliah di luar negeri (Lee et al., 2013; Li et al., 2014). Ward dan Kennedy (1993) meneliti mahasiswa Malaysia dan Singapura yang menempuh studi di Selandia Baru. Pedersen et al. (2011) mengkaji penyesuaian diri mahasiswa Amerika Serikat yang merantau. Faktor-faktor penyesuaian sosial mahasiswa internasional di Turki diteliti oleh Gündüz dan Alakbarov (2019). 
Ada beberapa penelitian yang menyasar konteks perjumpaan antarbudaya mahasiswa Indonesia maupun mahasiswa internasional di Indonesia. Salah satunya adalah tentang strategi adaptasi mahasiswa perantau Bugis-Makassar di Melbourne, Australia (Solihin, 2013). Penelitian lain menelaah dan penggunaan terapi kelompok untuk mengatasi permasalahan penyesuaian sosial mahasiswa perantau (Amalia et al., 2017). Faizah dan Rifameutia (2019) menyebutkan bahwa mahasiswa perantauan di Indonesia dapat mengalami penurunan prestasi akademis akibat gegar budaya yang dialami dari pengalaman berpindah dari daerah asalnya. Jaenudin et al. (2020) meneliti mahasiswa asal Thailand yang berkuliah di Bandung.

Penelitian ini mendalami sampel mahasiswa perantauan yang tinggal di asrama salah satu universitas swasta di Yogyakarta. Tampaknya belum ada penelitian yang menyasar konteks spesifik tersebut.

\section{Berbagai Tantangan Mahasiswa Perantauan di Yogyakarta}

Mahasiswa perantauan di Yogyakarta berasal dari berbagai daerah. Ada kesamaan dan perbedaan tema tantangan menyesuaikan diri di Yogyakarta berdasarkan daerah asal perantau. Perantau dari daerah Papua (Kumoro, 2017; Mahyuddin, 2018) dan Kalimantan Barat (Kumoro, 2017), Sumatra Barat (Kuncorowati et al., 2018), Sumatra Utara (Simatupang et al., 2015), Aceh (Liyana, 2017), dan luar negeri (Pradita, 2013) sama-sama menyebutkan tema bahasa dalam penuturan pengalamannya. Penelitian tentang perantau dari Aceh dan Sumatra Barat tidak mengandung informasi tentang tekanan yang dirasakan perantau tentang bahasa lokal Yogyakarta. Penelitian tentang perantau dari daerah lainnya menyebutkan bahwa kesalahpahaman bahasa merupakan salah satu kendala dalam menyesuaikan diri hidup di Yogyakarta.

Penelitian-penelitian berdasarkan daerah asal perantau menunjukkan keberagaman pengalaman mahasiswa perantauan di Yogyakarta berdasarkan suku atau daerah asalnya, juga berdasarkan topik yang disasar peneliti. Penelitian ini menyasar mahasiswa perantauan yang tinggal di asrama salah satu universitas swasta di Yogyakarta. Belajar dari penelitian-penelitian yang telah disebutkan di atas, dapat disimpulkan bahwa konteks daerah asal mahasiswa perlu dipertimbangkan dalam meneliti pengalaman mahasiswa perantauan.

Telah diuraikan bahwa mahasiswa perantauan pada umumnya mengalami gegar budaya saat terlibat dalam perjumpaan antarbudaya di daerah perantauannya. Intervensi diperlukan untuk membantu perantau menyesuaikan diri. Penelitian tentang pengalaman perantau diperlukan agar intervensi efektif. Berbagai penelitian perjumpaan antarbudaya mahasiswa perantauan yang ada selama ini mengkaji berbagai sampel mahasiswa perantauan tanpa mendalami tiap sampelnya, menggunakan paradigma kuantitatif, dan dilakukan dalam konteks internasional. Ini membuka celah terhadap penelitian yang sifatnya mendalami sampel tertentu, menggunakan paradigma kualitatif, dan dilakukan dalam konteks lokal. 
Penelitian ini dapat mengisi celah tersebut. Sampel yang didalami dalam penelitian ini adalah mahasiswa residen asrama kampus. Penelitian ini berparadigma kualitatif interpretatif, menggunakan pendekatan analisis tematik. Konteks lokalnya adalah Yogyakarta dan daerah asal mahasiswa.

Penelitian ini bertujuan untuk mengeksplorasi tema-tema pengalaman perjumpaan antarbudaya mahasiswa perantauan penghuni asrama salah satu universitas swasta di Yogyakarta. Pertanyaan penelitian adalah dalam konteks mahasiswa perantau residen asrama salah satu universitas swasta di Yogyakarta, tema-tema pengalaman perjumpaan antarbudaya apa saja yang dapat ditemukan?

\section{Kerangka Konseptual}

Teori psikologi gegar budaya (Ward et al., 2001) menyebutkan bahwa fenomena perjumpaan antarbudaya dalam diri perantau mencakup tiga tahapan, yaitu masukan (input), proses pengolahan (throughput), dan keluaran (output). Pada tahapan masukan, perantau membawa dalam dirinya faktor-faktor individual (mis.: kepribadian, identitas budaya, kemampuan berbahasa) dan faktor-faktor kemasyarakatan (misal: situasi politis, ekonomis, sosial, budaya daerah asal). Perantau tersebut kemudian bertempat tinggal sementara di daerah baru; terjadilah perubahan dalam hidupnya dan perjumpaan antarbudaya di daerah perantauan sebagai sebuah proses pengolahan (throughput).

Dalam proses itu, perantau mengalami berbagai stres dan ke-kurang-terampil-an beradaptasi; dia juga akan menanggapi dari sisi afeksi, kognisi, dan perilakunya. Dampak (output) dari proses pengolahan tersebut ada yang bersifat psikologis dan ada yang bersifat sosiokultural. Perkembangan terbaru teori ini mengganti istilah gegar budaya menjadi akulturasi dan memasukkan konteks sosio-ekologis dalam faktor-faktor kemasyarakatan (Ward \& Geeraert, 2016).

Akulturasi. Akulturasi adalah proses kognisi, afeksi, dan perilaku yang terjadi dalam diri perantau ketika mengalami perpindahan dari daerah asalnya ke daerah perantauan, di mana dia mengalami perjumpaan antarbudaya dengan masyarakat setempat yang budayanya berbeda dengan budaya daerah asalnya (Ward et al., 2001; Ward \& Geeraert, 2016). Unsur-unsur pembentuk konstruk akulturasi disusun oleh Ward et al. (2001) dari beberapa variabel penelitian-penelitian terdahulu. Kajian-kajian mengenai pemahaman lintas-budaya, identitas sosial, dan strategi akulturasi menjadi unsur pembentuk aspek kognisi. Kajian tentang stres, penanganan stres, kepribadian, dan perubahan hidup menjadi unsur pembentuk aspek afeksi. Terakhir, kajian terkait keterampilan penyesuaian diri dan komunikasi antarbudaya disusun menjadi aspek perilaku. Penelitian ini akan menggali pengalaman mahasiswa dari sisi kognisi, afeksi, dan perilakuan sesuai teori akulturasi. 
Tema-tema Pengalaman Mahasiswa Perantauan. Tinjauan dari berbagai penelitian menunjukkan tema-tema pengalaman yang sangat variatif. Kudo et al. (2017) menggali empat tema besar dalam interaksi antarbudaya antara mahasiswa dan lingkungannya terkait hambatan dan pendukung di level pribadi dan kemasyarakatan. Mahasiswa internasional di Turki memperlihatkan tema-tema perasaan aman, terlibat dalam kegiatan sosial, penggunaan jasa konseling, dan komunikasi dengan dosen (Gündüz \& Alakbarov, 2019).

Tema-tema mahasiswa asal Singapura dan Malaysia di Selandia Baru di antaranya penempatan kendali diri (locus of control), kepuasan relasi dengan penduduk setempat, jarak budaya, dan corak kepribadian ekstrovert (Ward \& Kennedy, 1993). Tema-tema mahasiswa Asia Timur yang menuntut ilmu di perguruan tinggi luar negeri terkait kesulitan akademis (Lee et al., 2013; Li et al., 2018) dan kesejahteraan psikologis (Li et al., 2014).

Berbagai tema tersebut mengindikasikan bahwa setiap konteks daerah asal dan daerah tujuan perantauan memiliki kekhasan dalam hal-hal apa yang dianggap menonjol dan relevan bagi mahasiswa perantauan. Dengan begitu, jika ada pihak yang ingin merancang intervensi terhadap mahasiswa perantauan, maka pihak itu perlu mengintegrasikan tema-tema kontekstual dalam perancangannya.

Intervensi Keterampilan Akulturasi Mahasiswa Perantauan. Berbagai intervensi dikembangkan demi membantu mahasiswa perantauan menyesuaikan diri di daerah perantauan. Intervensi dapat berupa psikoterapi atau konseling (Amalia et al., 2017; Tohidian \& Quek, 2017), pelatihan kompetensi antarbudaya (Deardorff, 2009; Jackson, 2015), dan pengembangan kurikulum pengajaran di pendidikan tinggi (Otten, 2003; Punteney, 2016). Penelitian ini berfokus pada pelatihan kompetensi antarbudaya, karena pelatihan atau psikoedukasi semacam itu yang disarankan oleh penggagas teori psikologi gegar budaya (Ward et al., 2001). Penelitian ini juga merupakan bagian dari rangkaian kegiatan perancangan psikoedukasi keterampilan budaya mahasiswa residen asrama di salah satu universitas swasta di Yogyakarta.

Spitzberg dan Changnon (2009) mengulas berbagai teori dan model kompetensi antarbudaya dan menemukan bahwa kebanyakan model menggunakan konteks sebagai salah satu komponen utama. Model dianggap semakin bagus jika mengonsepkan minimal lima komponen, di antaranya komponen konteks, dan diterapkan dalam hubungan nyata seiring waktu (Spitzberg \& Changnon, 2009, p. 44). Penelitian ini mengeksplorasi tema-tema pengalaman mahasiswa perantauan dalam rangka memenuhi komponen konteks dalam kerangka konseptual psikoedukasi kompetensi antarbudaya itu. 


\section{Metode}

Penelitian ini merupakan bagian dari proses perancangan intervensi berupa psikoedukasi keterampilan antarbudaya bagi mahasiswa residen salah satu asrama kampus universitas swasta di Yogyakarta. Tema-tema yang dihasilkan dari penelitian ini sangat berguna untuk menyusun materi psikoedukasi yang relevan dengan pengalaman nyata partisipan (Jackson, 2015).

Pendekatan yang digunakan adalah kualitatif. Ada tiga dimensi dari pendekatan ini yang perlu dicantumkan secara eksplisit, yaitu sistematika penyimpulan, level analisis, dan epistemologi (Braun \& Clarke, 2006). Sistematika penyimpulan penelitian ini menggunakan pendekatan induktif. Level analisis berada pada tingkat interpretatif. Terkait epistemologi, penelitian ini menggunakan pendekatan realis.

\section{Partisipan}

Sebanyak 59 mahasiswa residen asrama, 26 laki-laki dan 33 perempuan, berpartisipasi dalam penelitian ini. Partisipan berasal dari daerah Papua, Mentawai, dan Ketapang. Peneliti dibantu oleh pamong dalam menanyakan kesediaan partisipan. Pamong adalah pekerja asrama yang bertugas mendampingi secara langsung para mahasiswa dalam keseharian kegiatan asrama. Dari total 100 mahasiswa tahun pertama asrama yang ditargetkan, 57 mahasiswa bersedia mengikuti diskusi kelompok terarah (FGD).

FGD dilakukan dalam dua kesempatan, 22 November 2019 dan 30 November 2019. Pada kesempatan pertama, 21 mahasiswa berpartisipasi, dibagi dalam dua kelompok secara acak dengan mempertimbangkan keseimbangan proporsi laki-laki dan perempuan. Maing-masing kelompok difasilitasi oleh satu orang, yaitu peneliti dan rekan kerja peneliti. Kedua fasilitator adalah dosen fakultas psikologi.

Pada kesempatan kedua, 36 mahasiswa berpartisipasi, dibagi dalam tiga kelompok secara acak dengan mempertimbangkan keseimbangan proporsi laki-laki dan perempuan. Masing-masing kelompok didampingi oleh satu orang, yaitu peneliti, rekan kerja peneliti, dan asisten peneliti. Peneliti dan rekan kerja peneliti adalah dosen. Asisten peneliti merupakan mahasiswa psikologi tingkat akhir yang telah dipersiapkan untuk memfasilitasi.

\section{Prosedur}

Data dikumpulkan melalui FGD. Sebelum FGD dilaksanakan, peneliti menjelaskan topik penelitian ini secara lisan, lalu peserta mengisi lembar pernyataan kesediaan (informed consent). Pada lembar kesediaan terdapat penjelasan singkat topik penelitian ini.

FGD dilakukan selama 90 sampai 150 menit. Panduan diskusi dikembangkan dari kerangka konseptual penelitian ini, yaitu 1) mengapa kuliah di Yogyakarta, 2) apa yang dialami saat awal-awal berada di Yogyakarta, 3) bagaimana kesan terhadap orang dan budaya Yogyakarta, 4) pengalaman berinteraksi dengan orang Yogyakarta, dan 5) apa kesulitan akademik yang dialami. 
Semua sesi diskusi direkam suaranya. Rekaman suara lalu ditranskrip. Semua transkrip dimasukkan ke aplikasi QDA Miner Lite untuk dianalisis.

\section{Analisis data}

Data diolah menggunakan teknik analisis tematik (Braun \& Clarke, 2006, 2014). Aplikasi QDA Miner Lite digunakan untuk membantu proses analisis.

\section{Hasil}

Para partisipan pada umumnya memiliki idealisme meningkatkan status sosial-ekonomi keluarga sendiri dan masyarakat daerah asal, mengalami stres akulturasi terkait makanan, kondisi geografis, pemahaman bahasa dan keterampilan komunikasi, dan stereotip, lalu berusaha mengatasi stres akulturasi tersebut dengan berbagai kegiatan jejaring sosial. Nama partisipan dan orang-orang yang disebutkan di uraian ini disamarkan. Partisipan laki-laki disamarkan menggunakan nama spesies burung, partisipan perempuan menggunakan nama spesies bunga.

\section{Idealisme}

Semua mahasiswa residen asrama didanai dari beasiswa daerah. Umumnya para mahasiswa ini berada dalam keluarga yang kondisi ekonominya kurang mampu untuk menyekolahkan mereka ke jenjang S1. Kuliah di perantauan, bagi mereka, adalah perjuangan untuk meningkatkan status sosial ekonomi keluarga.

Setelah lulus SMA saya tidak ada rencana untuk kuliah karena keterbatasan ekonomi dan kemudian ada dari romo paroki saya meminta untuk bertemu dengan saya karena saya sering aktif di gereja. Dan waktu itu ditawari, kamu mau gak ikut ini. Ada beasiswa kuliah di [kampus X]. Saya coba daftar. Saya urus semuanya. (Alamanda)

Selain dorongan sosial-ekonomi, mahasiswa juga didorong oleh idealisme terhadap daerah asalnya. Umumnya mereka kuliah di jurusan keguruan. Mereka mengakui bahwa saat ini di daerah asal mereka terdapat kekurangan jumlah guru.

Saya itu...yang membuat saya senang itu saya berpikir kembali. ...saya berpikir, di kampung saya, ketika saya dulu SD, di kampung saya itu cuman satu guru SD saya mengajar. Jadi saya berpikir kembali ke [daerah asal saya], ke kampung saya itu, saya dapat di sini kuliah, tamat jadi guru. Jadi saya harus kuliah, harus sukses menjadi guru yang baik. Saya bisa menjadi guru di kampung saya. Saya yang mengajar dulu di kampung saya itu cuman satu guru saja. (Nuri) 
Profesi guru mendapatkan status sosial yang tinggi di daerah asal mereka. Guru adalah simbol kemajuan, yang masyarakat daerah harapkan menjadi tokoh penting dalam proses mengangkat putra-putri daerah dari keterpurukan kondisi daerah saat ini.

Nah di sana itu, (masyarakat daerah asal menganggap) guru itu penting agar pendidikan lebih maju. Karena kan kalau di sana...pendidikannya ketinggalan. Nah sehingga masyarakat di sana itu punya pendapat ... pemikiran bahwa guru itu harus diutamakan. (Mawar)

\section{Makanan}

Partisipan cenderung mengalami ketidakcocokan selera terhadap makanan khas Yogyakarta. Menurut mereka, rasa makanan di Yogyakarta cenderung manis, sedangkan makanan daerah asal mereka cenderung asin dan pedas.

Awal datang kami kan makan...makannya memang manis-manis. Kadang saya juga tidak makan. Sempat sakit juga karena manis kemanisan. (Mawar)

...Kami makan di semua tempat, ya daun pepaya itu pahit. Tapi, di Jogja (daun pepaya) manis. Sambel ya pedas, juga ya sama. Gak pedas juga. Manis. Makanya bingung kami. (Kareo)

Meskipun begitu, beberapa partisipan mengakui tidak begitu memedulikan rasa. Yang penting harganya murah dan bisa makan banyak.

Pemandu FGD: Kalau Gagak, ... Kalau lagi banyak pikiran, atau lagi stress, gimana bikin semangat (lagi)?

Gagak: Kalau saya senang makan. ...Kalau di daerah asal, harga makanan mahal. ... kalau di sini murah.

Pemandu FGD: Tapi rasanya gimana? Katanya (cenderung) manis?

Gagak: Yang penting harganya murah. Kalau murah pasti enak jadinya.

\section{Kondisi Geografis}

Salah satu ciri khas Yogyakarta adalah masyarakatnya umumnya memiliki orientasi arah. Mereka cenderung menggunakan istilah-istilah arah mata angin, yaitu utara, selatan, timur, dan barat dalam menggambarkan letak suatu lokasi. Partisipan memiliki pengalaman bingung ketika dihadapkan pada istilah-istilah tersebut, karena biasanya di daerah asal mereka hanya menggunakan istilah kiri dan kanan sebagai orientasi geografis. 


\section{THEODORUS I| PERJUMPAAN ANTARBUDAYA}

...lalu yang lain itu ada rasa jengkelnya juga. Itu pada saat saya bersama teman-teman, itu pulang dari kampus, hari pertama-pertama. Itu kami kebingungan mau ke sini, ke asrama. Kita tanya, mereka itu pakai apa...utara, timur, hahaha... Mereka tuh pakai selatan, timur...kami tidak tau. Kalau kami kan biasa pake apa kiri kanan. Rasa jengkel juga, tapi mau bagaimana lagi. (Kasuari)

Suasana alam Yogyakarta menurut beberapa partisipan sangat berbeda dengan daerah asalnya, misalnya perkara terbitnya matahari dan suhu udara.

...Ada yang aneh. Kalau menurut saya ada yang aneh. Jam 7 itu matahari sudah sangat siang. Sudah lebih panas iya. Tapi kalau di sini kok masih [kurang begitu terang]. Makanya kita tarik selimut (kembali tidur) karena suasana kayak beda gitu. (Rajawali) Di sini aneh juga sih. Suasananya dingin tapi kipas angin sama AC-nya masih jalan. Kalau di sana (daerah asal), siang, kepanasan baru (menyalakan) AC. Di sini mendung, dingin, kipas angin sama AC jalan lagi. Jadi seperti di dalam kulkas. Setiap kali ke kampus saya selalu pake sweater. (Sikep)

Kemudian saya pernah sakit. Sakit karena penyesuaian cuaca juga. Udara di daerah asal saya dan di sini itu beda. (Anggrek)

Ada juga partisipan yang berasal dari daerah terpencil, sehingga terkagum-kagum dengan bangunan tinggi di Yogyakarta.

[Ketika awal-awal] saya sampai di sini (Yogyakarta) tuh, kesanku tuh...(terheran-heran) bangunannya tinggi-tinggi, terus ada jembatan layangnya. (Nila)

\section{Kendala Bahasa dan Keterampilan Komunikasi dalam Proses Belajar Mengajar}

Partisipan seringkali mengalami kesulitan memahami penjelasan dosen. Dosen seringkali menggunakan kata-kata dalam bahasa Jawa dalam mengajar dan memberikan instruksi tugas. Partisipan juga merasa dosen kurang mau memahami perspektif mahasiswa perantau. Partisipan juga segan untuk bertanya.

Kalau saya hmm...bertanya sama dosen. Malu bertanya sama dosen. Mengapa malu, sebenarnya tidak semua mata kuliah, tapi cuma satu. Aa biasanya Pak [Alap-alap] itu tidak terlalu kebanyakan materi, tapi kebanyakan tugas. Tugas itu selalu dijelaskan, tapi aku tidak paham. Sehingga saya itu bagaimana ya...mau bertanya, di sisi lain takutnya nanti salah. (Mawar)

Sama kayak kelas kami sudah ditandai sama dosen-dosen. Kalau presentasi kelas kami tu singkat-singkat jadi (kami dikatakan) malas gitu. Dari mana tahu kalau ada perbedaan 


\section{THEODORUS I I PERJUMPAAN ANTARBUDAYA}

malas gitu loh? Dosennya sendiri yang bilang. Kami kalau kerja tugas kayak tidak niat. Terus kalau ada yang mau tanya atau mau jawab, pasti kayak dibuli gitu loh. (Jalak)

Beberapa partisipan merasa malu untuk aktif di kelas karena logat daerahnya.

Sama kayak [si $M$ ], saya malu mau bertanya dan ragu karena logat saya yang masih terbiasa dengan logat (daerah Timur). Terus nanti kalau saya bertanya, nanti pendapat saya tidak sama kayak teman-teman. Jadi saya tahan begitu. (Iris)

Ada partisipan yang merasa terganggu saat kerja kelompok teman-teman terkesan tidak peduli bahwa dia tidak mengerti bahasa Jawa.

...Terus di kampus itu, saya tidak sukanya itu teman-teman macam ada diskusi kelompok ada tugas kelompok teman-teman Jawa itu berbicara dengan bahasa Jawa, karena kan kalau itu kan kerja kelompok kalau mereka berbicara dengan bahasa Jawa kita nanti tidak mengerti apa-apa begitu. (Elang)

Selain isu cara mengajar dosen dan perlakuan teman kerja kelompok, ada juga pengakuan dari beberapa partisipan tentang sulitnya memahami bahasa Jawa dan bahasa Inggris. Padahal bahasa Jawa sering digunakan dalam percakapan di keseharian dan di dalam kelas, dan bahasa Inggris sering digunakan dalam bahan bacaan kuliah.

Kalau saya, budaya Jogja tuh, buat saya itu semakin buat sulit untuk bergaul di budaya sini. Semua orang pakai bahasa Jawa, tidak pakai Bahasa Indonesia. (Trinil)

Berhadapan dengan Stereotip dan Prasangka Masyarakat Setempat

Kebanyakan partisipan mengalami kesulitan bahasa saat berkomunikasi dengan masyarakat daerah perantauan. Partisipan mengakui bahwa meskipun sama-sama menggunakan bahasa Indonesia, logat daerah asal tetap berbeda dengan logat yang umumnya digunakan di Yogyakarta.

Tapi rasa anehnya itu pas sampai di sini itu... seperti bagaimana cara kita mau ngomong sama orang-orang di Jawa sini. Soalnya kan, gaya berbicara kami kan kasar. Jadi takutnya kalau kami berbicara kasar, tanggapan masyarakat di sini mungkin kami marah. Itu juga kadang membuat saya merasa kesulitan bagaimana untuk menghadapi situasi budaya, bahasa setempat. (Mawar) 


\section{THEODORUS I I PERJUMPAAN ANTARBUDAYA}

Ketika berinteraksi dengan masyarakat setempat, ada partisipan yang dinasihati oleh penduduk supaya tidak menjadi seperti yang dibayangkan orang Yogyakarta pada umumnya.

Emm terus bapak itu bilang. Gini nak, emm kebanyakan orang Jawa di sini tuh mereka cara pandangnya itu dilihat dari sisi perilaku. Kenapa dikatakan perilaku, karena di Jogja sini ya, kalau untuk orang Timur itu katanya kebanyakan pertama miras. ...kasar, ... nakal. (Melati)

Bahkan ada partisipan yang merasa dirinya dianggap sama dengan monyet oleh warga sekitar.

...Anak-anak panti asuhan pas liat saya mereka langsung eh monyet-monyet, bilang monyet begitu pas itu... Langsung saya bilang teman-teman ... lain kali [saya] tidak ikut [saja]... (Bakung)

Partisipan merasa jengkel dan terganggu terhadap pernyataan-pernyataan stereotip dan prasangka tersebut.

\section{Jejaring Sosial}

Para partisipan memiliki jejaring sosial yang membantu mereka melewati masa-masa sulit di perantauan. Ada partisipan yang melakukan usaha membaur dengan warga Yogyakarta. Usaha membaur tersebut diakui partisipan membuat mereka jadi lebih punya gambaran tentang konteks sosial budaya Yogyakarta, dan punya kenalan baru.

Kalau untuk saya itu, cara mengatasi (stres di perantauan) itu kan biasanya ... saya dan teman saya itu, sore-sore kami kan suka sering jalan-jalan. Nah terus emm...biasanya kan di Malioboro tuh di pinggir jalan ada tukang jual makanan, angkringan...gitu kan. Jadi kami tuh sering suka beli gorengan sambil ngobrol dengan masyarakat di situ. Nah...di situ emm... saya kan secara perlahan-lahan, saya menyadari bahwa... ada penyesuaian. Nah penyesuaian diri dengan lingkungan setempat dari banyak bicara. (Mawar)

Ada partisipan yang merasa percaya dengan orang-orang Yogyakarta tertentu untuk menceritakan keluh kesah yang dialami oleh partisipan.

Nila: Pada awal tiba di Yogyakarta] ada bapak yang jaga kami (petugas di asrama), namanya Pak Delimukan ... [saya] suka cerita sama dia.

Pemandu FGD: Pak Delimukan ini orang Jogja?

Nila: orang Jawa... dia itu baik, ... Penyayang. Jadi akhirnya aku berani bercerita dengan dia. [Dia] jadi teman saya. 
Umumnya partisipan memiliki kesan yang menyenangkan dalam bergaul dengan teman-teman mahasiswa, baik mahasiswa setempat, mahasiswa sesama perantau namun bukan dari daerah asal.yang sama, maupun sesama perantau dari daerah asal. Kegiatan yang populer dilakukan bersama teman-teman itu adalah olahraga atau jalan-jalan.

Dari berbagai jejaring sosial partisipan, umumnya yang dianggap paling berharga dan diharapkan dukungannya adalah dari anggota keluarga inti, yaitu ayah, ibu, atau saudara kandung.

Bagi saya, mama saya yang biasa membantu saya pas kesulitan .... seperti misal saya kurang paham begitu...atau gimana bergaul dengan teman, biasanya saya ... tanya sama mama. Semacam curhat begitu, jadi mama itu jadi teman curhat saya. (Melati)

Masih banyak lagi kutipan data yang senada dengan kutipan di atas. Bahkan beberapa kutipan data menggambarkan intensitas emosional yang sangat tinggi, misalnya merasa sangat sedih terpisah dari keluarga, lalu menangis-nangis saat bertelepon dengan ibu, dan di akhir pembicaraan merasa sedikit lega dan terobati rasa kangennya.

Ada juga partisipan yang merasa lebih dekat dengan kakaknya setelah merantau.

Lily: emm pertama-tama saya menginjakkan kaki di kota Jogja, saya merasa senang ... karena bisa bertemu dengan kakak saya.

Pemandu FGD: Oh, kakak udah di sini sebelumnya?

Lily: Iya. Pas ... masih sekolah di SMA, saya merindukan dia. Maunya bersama dia. Karena kami tidak pernah berpisah. Jadi pas dia ke sini kuliah duluan, tahun 2017, saya bilang, kakak saya mau datang untuk sama-sama dengan kakak juga di sini. Jadi saya merasa senang.

Meskipun begitu, ada partisipan yang mengaku lebih senang berteman dengan sesama perantau dari daerah asal karena berteman dengan mahasiswa setempat membutuhkan usaha lebih banyak.

...Emm kalau pribadi saya itu saya lebih cocok itu dengan teman daerah asal saya. Maksudnya kita ngobrolnya itu apa...kaya macam pendapat kita itu sama begitu. Kalau orang Jawa itu nanti kita menjelaskan lagi maksud kita seperti ini, jadi saya harus menjelaskan supaya mereka bisa tahu apa yang kita bicarakan. (Emprit)

\section{Diskusi}

Penelitian ini diarahkan untuk menjawab pertanyaan penelitian tentang tema-tema pengalaman perjumpaan antarbudaya apa saja yang dapat ditemukan dalam konteks 
mahasiswa perantau residen asrama salah satu universitas swasta di Yogyakarta. Ragam tema yang ditemukan dalam penelitian ini ada kesamaan dan perbedaan dengan beberapa penelitian dalam konteks lain. Isu-isu akademis, pertemanan, dan bahasa dapat ditemukan di berbagai konteks, misalnya konteks mahasiswa asal Indonesia di Jerman (Yuniarti, 2010), mahasiswa asal Jepang dan Korea di Thailand (Rhein \& Jones, 2020), dan mahasiswa perantauan dari berbagai negara yang berkuliah di Amerika Serikat (Shu et al., 2020). Tema yang khas dalam penelitian ini adalah makanan, kondisi geografis, dan idealisme. Ini dapat saja menandakan bahwa dalam konteks Yogyakarta, rasa aman dan nyaman mahasiswa perantau lebih disandarkan pada ketiga hal tersebut daripada hal-hal lain yang muncul dalam konteks penelitian lain.

Mahasiswa perantau residen asrama di Yogyakarta merasakan kondisi psikologis yang kurang nyaman terkait makanan. Makanan merupakan bagian dari beberapa tema yang dikaji dalam Sociocultural Adaptation Scale (Ward \& Kennedy, 1999; Wilson et al., 2017). Penelitian-penelitian sebelumnya lebih menyasar aspek psikometrik dari skala itu sehingga penjelasan mengenai makanan dan kondisi geografis sangat singkat. Disebutkan bahwa kemampuan menikmati makanan setempat dan membuat diri nyaman dengan kondisi geografis daerah perantauan merupakan aspek dari kemampuan adaptasi sosiokultural. Data dari penelitian ini mengindikasikan bahwa para mahasiswa perantauan masih mengalami kesulitan dalam dua wilayah kemampuan adaptasi tersebut.

Urusan makanan sebenarnya tidak sekadar perkara mengenyangkan perut dan memenuhi kebutuhan gizi saja. Makan bersama dapat menjadi sarana keakraban dan memakan makanan daerah asal dapat menimbulkan suasana nostalgia akan daerah asal (Brown et al., 2019; Hartwell et al., 2011). Rasa tidak suka terhadap masakan khas Yogyakarta kemungkinan timbul dari pembentukan kebiasaan yang sangat kuat dalam mengonsumsi makanan daerah asal (Cervellon \& Dubé, 2005). Kebiasaan itu kemudian memicu mahasiswa perantau untuk menutup diri terhadap berbagai rasa yang baru dan tidak familiar dari makanan daerah perantauan.

Hubungan dengan anggota keluarga inti tampaknya memegang peranan sangat penting bagi mahasiswa perantauan. Ini berbeda dengan penelitian (Shu et al., 2020) yang menyatakan bahwa dukungan sosial dari keluarga kurang signifikan, dibandingkan dengan hubungan dengan teman dan institusi pendidikan. Kemungkinan ini merupakan akibat dari mahasiswa perantauan dalam konteks penelitian ini cenderung belum mampu menjalin relasi mendalam dengan jejaring sosial selain keluarga. Bagaimanapun juga, mahasiswa perantauan perlu meningkatkan kedekatan hubungan dalam jejaring sosial dengan teman sesama perantauan, teman mahasiswa setempat, penduduk lokal, dan dosen karena relasi tersebut merupakan bagian dari keterampilan adaptasi sosiokultural (Wilson et al., 2017).

Bagi mahasiswa perantauan, idealisme meningkatkan status sosial-ekonomi keluarga sendiri dan masyarakat daerah asal membuat mereka bertahan melanjutkan 
studi di daerah perantauan. Idealisme ini sejalan dengan konsep afirmasi diri (selfaffirmation), yaitu menyatakan tujuan dan nilai-nilai yang dianggap berharga bagi diri seseorang secara gamblang dan lugas. Afirmasi diri memotivasi seseorang untuk berjuang mencapai nilai-nilai ideal yang diyakininya, dan dengan begitu menjaga keutuhan jati dirinya (Cohen et al., 2006; Ferrer \& Cohen, 2019; Hall, 2012). Tema idealisme ini perlu ditekankan lagi pada mahasiswa perantauan, supaya mereka bertahan dan menyelesaikan studinya lalu kembali berkontribusi bagi daerah asalnya. Afirmasi diri juga perlu dirasakan mendesak oleh mahasiswa perantau. Seringkali orang memiliki idealisme namun dalam level normatif saja, tidak benar-benar dijiwai.

Konsep afirmasi diri berkaitan erat dengan tema ancaman stereotip. Ancaman stereotip adalah ketidaknyamanan psikologis yang timbul akibat kekhawatiran bahwa diri sendiri akan menjadi seperti yang distereotipkan dan diprasangkai oleh orang-orang (Steele, 1997). Mahasiswa perantauan di penelitian ini mengalami stereotip dan prasangka dari masyarakat setempat, termasuk dosen. Pengalaman dikenai stereotip dan prasangka oleh masyarakat setempat dapat berakibat depresi, kesedihan, dan ketidakberdayaan (Branscombe et al., 1999), penurunan prestasi akademis (Walton \& Spencer, 2009), keengganan untuk mengekspresikan diri apa adanya (Cook et al., 2011), juga memancing berbagai perilaku kenakalan (Loyd et al., 2019). Oleh karena itu, proses psikoedukasi perlu menyasar tema ini agar ancaman stereotip yang dialami oleh mahasiswa perantau dapat diarahkan menjadi hal-hal yang adaptif (Murphy et al., 2020; Stanciu \& Vauclair, 2018). Salah satu pendekatan psikoedukasi untuk mengatasi dampak buruk ancaman stereotip adalah pendekatan afirmasi diri (Goyer et al., 2019).

Ada dua tema terkait proses belajar mengajar yaitu peminggiran mahasiswa perantauan dan keterampilan komunikasi antarbudaya antara mahasiswa dan dosen. Dalam hal peminggiran budaya, pengalaman mahasiswa perantauan di penelitian ini sejalan dengan pengalaman mahasiswa Aborigin di Australia (Sonn et al., 2000). Baik mahasiswa Aborigin maupun mahasiswa perantauan di penelitian ini mengalami keterkejutan budaya, disorientasi di lokasi baru yang tidak familiar, tercerabut dari kedekatan fisik dengan keluarga, dan tuntutan perubahan kebiasaan makan. Mereka juga mengalami perlakuan kurang sensitif budaya dari dosen dan mahasiswa berlatar belakang budaya dominan di daerah perantauan, yang cenderung kurang memahami atau peduli dengan budaya asli mahasiswa perantau. Akibatnya, banyak mahasiswa Aborigin yang tidak bertahan melanjutkan studi (Hearn et al., 2019). Beberapa pakar pendidikan tinggi di Australia mulai menyadari hal ini dan mengembangkan berbagai pendekatan untuk mengatasinya (Rochecouste et al., 2017). Pengembangan psikoedukasi mahasiswa perantauan dapat mengambil pembelajaran dari berbagai pendekatan tersebut.

Tema terakhir adalah keterampilan komunikasi antarbudaya. Mahasiswa perantau di penelitian ini memiliki pengalaman buruk terkait cara berkomunikasi, terutama antara mereka dengan dosennya. Mereka mengalami kesulitan memahami isi 
pesan yang disampaikan dosen di kelas, dan dari pihak dosen pun kurang sensitif budaya dalam menerangkan materi kuliah. Pengalaman ini disoroti dalam keterampilan antarbudaya (Wilson et al., 2017), juga dalam aspek manajemen identitas dan pemeliharaan hubungan dalam salah satu skala keefektifan komunikasi antarbudaya (Portalla \& Chen, 2010). Beberapa peneliti telah mencoba berbagai pendekatan untuk meningkatkan keterampilan komunikasi antarbudaya (Henderson et al., 2016; Yang, 2018). Pengembangan psikoedukasi antarbudaya mahasiswa perantau perlu belajar dari pengalaman para peneliti tersebut.

\section{Budaya Daerah Asal Mahasiswa Perantauan}

Mahasiswa perantauan dalam penelitian ini berasal dari daerah Mentawai, Kalimantan, dan Papua. Tema bahasa dan pengalaman diskriminatif di penelitian ini sejalan dengan pengalaman mahasiswa Papua di Surabaya (Wijanarko \& Syafiq, 2013), bahwa perbedaan tampilan fisik dan cara berkomunikasi antara orang Papua dan orang Jawa Timur cukup menghambat mahasiswa Papua dalam melakukan interaksi sosial di keseharian. Bagi mahasiswa asal Ketapang, tampaknya tema makanan yang menonjol. Ini dapat dipahami, karena makanan khas Ketapang tampaknya berbeda jauh dengan makanan yang umumnya tersedia di Y ogyakarta. Dalam suatu penelitian, misalnya, ditunjukkan bahwa mahasiswa Ketapang suka memasak daging biawak (Harmastuti et al., 2020). Tema pengalaman terkait kondisi geografis terlihat pada mahasiswa asal Mentawai. Di Yogyakarta cukup banyak terdapat bangunan modern, sedangkan di Mentawai kondisinya didominasi suasana alam dan pertanian (Efnita, 2018).

Dari uraian tentang kekhasan tema dan daerah asal mahasiswa di atas, dapat disimpulkan bahwa meskipun mahasiswa sama-sama dari luar Jawa, berada dalam satu asrama, dan berkuliah di universitas yang sama, tetap terdapat tema-tema tertentu yang lebih mengena pada diri mahasiswa sesuai kekhasan daerah asalnya. Semakin jauh perbedaan budaya dalam tema tertentu, semakin tinggi keterkejutan yang dirasakan mahasiswa.

\section{Kesimpulan}

Keenam tema yang ditemukan dalam penelitian ini, yaitu idealisme, makanan, kondisi geografis, pemahaman bahasa dan keterampilan komunikasi, stereotip, dan jejaring sosial, telah dibahas menggunakan perspektif psikologi akulturasi (gegar budaya), psikologi sosial afirmasi diri dan ancaman stereotip, peminggiran budaya, dan keterampilan komunikasi antarbudaya. Tema dan kajian tersebut perlu diperhatikan dalam perancangan psikoedukasi maupun kebijakan universitas terkait mahasiswa perantauan.

Kenyataan permasalahan di lapangan terkait mahasiswa perantau jauh lebih luas dan kompleks daripada yang diuraikan dalam artikel ini. Ini merupakan tantangan dan 
ajakan bagi para peneliti dan pembuat kebijakan untuk lebih meningkatkan lagi usahausaha promosi keterampilan antarbudaya di kampus dengan menggunakan berbagai pendekatan demi keberhasilan studi dan tercapainya idealisme mahasiswa perantau.

\section{Saran}

Penelitian ini menggunakan metode kualitatif. Seperti pada umumnya pendekatan kualitatif, temuannya tidak dapat digeneralisasi. Meskipun begitu, pencerahan yang muncul dari penelitian ini dapat dijadikan bahan pertimbangan untuk membuat kebijakan dan program psikoedukasi antarbudaya. Ini dikarenakan isu-isu yang muncul di penelitian ini benar-benar terjadi di kenyataan mahasiswa perantau pada sampel yang diteliti.

Sampel mahasiswa residen asrama suatu universitas swasta Yogyakarta digunakan dalam penelitian ini. Pengalaman mereka belum tentu sama dengan mahasiswa perantauan dalam sampel lain. Penelitian selanjutnya dapat menggunakan berbagai sampel mahasiswa perantauan Indonesia. Tambahan pengetahuan mengenai pengalaman mahasiswa perantauan dari berbagai daerah di Indonesia tentunya akan memperkuat basis kajian ilmiah psikologi mahasiswa perantauan, dan dengan begitu intervensi yang dikembangkan dari pengetahuan ini akan menjadi lebih efektif dan tepat sasaran.

Telah disebutkan di bagian awal artikel ini bahwa konteks merupakan salah satu hal inti yang penting dipertimbangkan dalam merancang intervensi berupa psikoedukasi keterampilan antarbudaya (Jackson, 2015; Spitzberg \& Changnon, 2009). Tulisan ini telah menguraikan tema-tema mendasar pengalaman mahasiswa perantauan dalam konteks daerah asal Ketapang, Mentawai, dan Papua yang merantau ke Yogyakarta, bertempat tinggal di asrama universitas, dan berkuliah di salah satu universitas swasta di Yogyakarta. Tema-tema idealisme, makanan, kondisi geografis, pemahaman bahasa dan keterampilan komunikasi, stereotip, serta jejaring sosial yang ditemukan dalam penelitian ini dapat diolah lebih lanjut menjadi isi materi pelatihan. Isi materi pelatihan yang otentik, kaya, dan relevan dengan pengalaman nyata peserta tentunya akan mendorong ketertarikan, keterlibatan, dan komitmen peserta dalam pelatihan (Jackson, 2015).

\section{Ucapan terima kasih}

Peneliti menyampaikan rasa terima kasih kepada Lembaga Penelitian dan Pengabdian kepada Masyarakat (LPPM) Universitas Sanata Dharma yang telah mendanai penelitian ini. Terima kasih juga kepada rekan kerja dan asisten peneliti yang sangat membantu proses penelitian, yaitu: Febriana Ndaru Rosita, Mirna Unisia Purwanto, Agnes Nona Bukan, Leonardus Leopodius Novantura, dan Visky Veronika S. 


\section{THEODORUS | | PERJUMPAAN ANTARBUDAYA}

\section{Kontribusi penulis}

ET merancang, menganalisis data, dan menulis manuskrip penelitian ini.

\section{Konflik kepentingan}

Peneliti tidak memiliki konflik kepentingan untuk diungkapkan.

\section{Pendanaan}

Penelitian ini didanai oleh LPPM Universitas Sanata Dharma.

orCid ID

Edward Theodorus 0000-0002-3166-020X

\section{Kepustakaan}

Amalia, F., Hanum, L., \& Sukarlan, A. D. P. (2017). Using group therapy to resolve social adjustment problems of sojourner students at Universitas Indonesia. In S. R. Asih, P. Newcombe, J. L. Suzana, M. N. Milla, L. R. M. Royanto, L. M. Boediman, D. E. Purba, M. D. Mustika, \& C. A. Dannisworo (Eds.), Proceedings of the 1st International Conference on Intervention and Applied Psychology (ICIAP), 2017 (pp. 307-318). Atlantis Press. https://doi.org/10.2991/iciap-17.2018.30

Branscombe, N. R., Schmitt, M. T., \& Harvey, R. D. (1999). Perceiving pervasive discrimination among African Americans: Implications for group identification and well-being. Journal of Personality and Social Psychology, 77(1), 135-149. https://doi.org/10.1037/0022-3514.77.1.135

Braun, V., \& Clarke, V. (2006). Using thematic analysis in psychology. Qualitative Research in Psychology, 3(2), 77-101. https://doi.org/10.1191/1478088706qp063oa

Braun, V., \& Clarke, V. (2014). What can "thematic analysis" offer health and wellbeing researchers? International Journal of Qualitative Studies on Health and Well-Being, 9(1), 26152. https://doi.org/10.3402/qhw.v9.26152

Brown, L., Farbrother, C., \& Dazam, J. (2019). Longing for a taste of home. British Food Journal, 121(12), 3281-3292. https://doi.org/10.1108/BFJ-03-2019-0179

Cervellon, M.-C., \& Dubé, L. (2005). Cultural influences in the origins of food likings and dislikes. Food Quality and Preference, 16(5), 455-460. https://doi.org/https://doi.org/10.1016/j.foodqual.2004.09.002

Cohen, G. L., Garcia, J., Apfel, N., \& Master, A. (2006). Reducing the racial achievement gap: A social-psychological intervention. Science, 313(5791), 1307-1310. https://doi.org/10.1126/science.1128317

Cook, J. E., Arrow, H., \& Malle, B. F. (2011). The effect of feeling stereotyped on social power and inhibition. Personality and Social Psychology Bulletin, 37(2), 165-180. https://doi.org/10.1177/0146167210390389

Deardorff, D. K. (Ed.). (2009). The SAGE handbook of intercultural competence. SAGE Publications, Inc.

Demes, K. A., \& Geeraert, N. (2015). The highs and lows of a cultural transition: A longitudinal analysis of sojourner stress and adaptation across 50 countries. Journal of Personality and Social Psychology, 109(2), 316-337. https://doi.org/10.1037/pspp0000046 
Doucerain, M. M. (2019). Moving forward in acculturation research by integrating insights from cultural psychology. International Journal of Intercultural Relations, 73, 11-24. https://doi.org/https://doi.org/10.1016/j.ijintrel.2019.07.010

Efnita, T. (2018). Pengaruh faktor sosial ekonomi dan kebutuhan hidup terhadap prestasi belajar mahasiswa Mentawai di Daerah Istimewa Yogyakarta. Jurnal Benefita, 3(1), 13-33.

Faizah, L., \& Rifameutia, T. (2019). Sojourner students' adjustment: Do they need to lower their normative achievement goal orientation to remain confident and survive? Hubs-Asia, 23(1), 73-83. https://doi.org/10.7454/hubs.asia.1120119

Ferrer, R. A., \& Cohen, G. L. (2019). Reconceptualizing self-affirmation with the trigger and channel framework: Lessons from the health domain. Personality and Social Psychology Review, 23(3), 285-304. https://doi.org/10.1177/1088868318797036

Goyer, J. P., Cohen, G. L., Cook, J. E., Master, A., Apfel, N., Lee, W., Henderson, A. G., Reeves, S. L., Okonofua, J. A., \& Walton, G. M. (2019). Targeted identity-safety interventions cause lasting reductions in discipline citations among negatively stereotyped boys. Journal of Personality and Social Psychology, 117(2), 229-259. https://doi.org/10.1037/pspa0000152

Greenfield, P. M. (2000). Three approaches to the psychology of culture: Where do they come from? Where can they go? Asian Journal of Social Psychology, 3(3), 223-240. https://doi.org/10.1111/1467-839x.00066

Greenfield, P. M. (2009). Linking social change and developmental change: Shifting pathways of human development. Developmental Psychology, 45(2), 401-418. https://doi.org/10.1037/a0014726

Greenfield, P. M. (2017). Cultural change over time: Why replicability should not be the gold standard in psychological science. Perspectives on Psychological Science, 12(5), 762-771. https://doi.org/10.1177/1745691617707314

Greenfield, P. M. (2018). Studying social change, culture, and human development: A theoretical framework and methodological guidelines. Developmental Review, 50, 16-30. https://doi.org/https://doi.org/10.1016/j.dr.2018.05.003

Gündüz, M., \& Alakbarov, N. (2019, 11/15). Analysis of social adjustment factors of international students in Turkey. Journal of International Students, 9(4), 1155-1171. https://doi.org/10.32674/jis.v9i4.917

Hall, C. C. (2012). Behavioral decision research, social class, and implications for public policy. In S. T. Fiske \& H. R. Markus (Eds.), Facing social class: How societal rank influences interaction (pp. 175-194). Russell Sage Foundation.

Harmastuti, A. W., Bahari, Y., \& Fatmawati. (2020). Toleransi antar mahasiswa berbeda etnik di asrama mahasiswa Ketapang Putra Kayong II Pontianak. Jurnal Pendidikan dan Pembelajaran Khatulistiwa, 9(10), 1-11.

Hartwell, H. J., Edwards, J. S. A., \& Brown, L. (2011). Acculturation and food habits: lessons to be learned. British Food Journal, 113(11), 1393-1405. https://doi.org/10.1108/00070701111180003

Hearn, S., Benton, M., Funnell, S., \& Marmolejo-Ramos, F. (2019). Investigation of the factors contributing to Indigenous students' retention and attrition rates at the University of Adelaide. The Australian Journal of Indigenous Education, Published online, 1-9. https://doi.org/10.1017/jie.2019.5 
Henderson, S., Barker, M., \& Mak, A. (2016). Strategies used by nurses, academics and students to overcome intercultural communication challenges. Nurse Education in Practice, 16(1), 71-78. https://doi.org/10.1016/j.nepr.2015.08.010

Jackson, J. (2015). Becoming interculturally competent: Theory to practice in international education. International Journal of Intercultural Relations, 48, 91-107. https://doi.org/10.1016/j.ijintrel.2015.03.012

Jaenudin, U., Sahroni, D., \& Ramdani, Z. (2020). Culture shock sebagai mediator antara kepribadian reformer terhadap sojourner adjustment. Psympathic: Jurnal Ilmiah Psikologi, 7(1), 117-128.

Kudo, K., Volet, S., \& Whitsed, C. (2017). Intercultural relationship development at university: A systematic literature review from an ecological and person-in-context perspective. Educational Research Review, 20, 99-116. https://doi.org/10.1016/j.edurev.2017.01.001

Kumoro, N. B. (2017). Batas yang tertutup dan yang terurai: Studi kasus batas etnis mahasiswa dari Papua dan Kalimantan Barat di Yogyakarta. In R. Tirtosudarmo (Ed.), Migrasi, politik dan etnisitas: Sebuah bunga rampai. Kentja Press.

Kuncorowati, P. W., Widihastuti, S., \& Nurhayati, I. (2018). Usaha perantau Minangkabau di Kota Yogyakarta dalam membina hubungan dengan kerabat asal. Jurnal Civics: Media Kajian Kewarganegaraan, 15(1), 26-36.

Lee, B., Farruggia, S. P., \& Brown, G. T. L. (2013). Academic difficulties encountered by East Asian international university students in New Zealand. Higher Education Research $\mathcal{E} \quad$ Development, 32(6), 915-931. https://doi.org/10.1080/07294360.2013.806444

Li, J., Wang, Y., Liu, X., Xu, Y., \& Cui, T. (2018). Academic adaptation among international students from East Asian countries: A consensual qualitative research. Journal of International Students, 8(1), 194-214. https://doi.org/10.32674/jis.v8i1.160

Li, J., Wang, Y., \& Xiao, F. (2014). East Asian international students and psychological well-being: A systematic review. Journal of International Students, 4(4), 301-313.

Liyana, C. I. (2017). Alih kode dan campur kode dalam komunitas mahasiswa perantauan Aceh di Yogyakarta. Community: Pengawas Dinamika Sosial, 3(2), 142-154.

Loyd, A. B., Hotton, A. L., Walden, A. L., Kendall, A. D., Emerson, E., \& Donenberg, G. R. (2019). Associations of ethnic/racial discrimination with internalizing symptoms and externalizing behaviors among juvenile justice-involved youth of color. Journal $\begin{array}{lll}\text { of } \quad \text { Adolescence, } & \text { 138-150. }\end{array}$ https://doi.org/https://doi.org/10.1016/j.adolescence.2019.07.012

Mahyuddin. (2018). Dinamika multikulturalisme mahasiswa Papua di Yogyakarta [Tesis Magister, Universitas Gadjah Mada]. Electronic Theses and Dissertations UGM. http://etd.repository.ugm.ac.id/penelitian/detail/157793

McKinley, M. T. (2019). Supervising the sojourner: Multicultural supervision of international students. Training and Education in Professional Psychology, 13(3), 174179. https://doi.org/10.1037/tep0000269

Murphy, M. C., Carter, E. R., Emerson, K. T. U., \& Cheryan, S. (2020). The long reach of prejudiced places? Stereotype expectations and motivation to pursue education among previously- and never-incarcerated black men. Self and Identity, 19(4), 456472. https://doi.org/10.1080/15298868.2019.1624605 
Otten, M. (2003). Intercultural learning and diversity in higher education. Journal of Studies in International Education, 7(1), 12-26. https://doi.org/10.1177/1028315302250177

Pedersen, E. R., Neighbors, C., Larimer, M. E., \& Lee, C. M. (2011). Measuring sojourner adjustment among American students studying abroad. International Journal of Intercultural Relations, 35(6), 881-889. https://doi.org/10.1016/j.ijintrel.2011.06.003

Portalla, T., \& Chen, G.-M. (2010). The development and validation of the intercultural effectiveness scale. Intercultural Communication Studies, 19(3), 21-37.

Pradita, I. (2013). A case study of forms and symptoms of culture shocks of the foreign students in Yogyakarta. Journal of English and Education, 7(1), 1-13.

Punteney, K. (2016). Deliberations on the development of an intercultural competence curriculum. Intercultural Education, 27(2), 137-150. https://doi.org/10.1080/14675986.2016.1145457

Rhein, D., \& Jones, W. (2020). The impact of ethnicity on the sociocultural adjustment of international students in Thai higher education. Educational Research for Policy and Practice, Online first article. https://doi.org/10.1007/s10671-020-09263-9

Rochecouste, J., Oliver, R., Bennell, D., Anderson, R., Cooper, I., \& Forrest, S. (2017). Teaching Australian Aboriginal higher education students: what should universities do? Studies in Higher Education, 42(11), 2080-2098. https://doi.org/10.1080/03075079.2015.1134474

Shu, F., Ahmed, S. F., Pickett, M. L., Ayman, R., \& McAbee, S. T. (2020). Social support perceptions, network characteristics, and international student adjustment. International Journal of Intercultural Relations, 74, 136-148. https://doi.org/https://doi.org/10.1016/j.ijintrel.2019.11.002

Simatupang, O., Lubis, L. A., \& Wijaya, H. (2015). Gaya berkomunikasi dan adaptasi budaya mahasiswa Batak di Yogyakarta. Jurnal ASPIKOM, 2(5), 314-329. https://doi.org/10.24329/aspikom.v2i5.84

Solihin, L. (2013). Mereka yang memilih tinggal: Telaah strategi adaptasi mahasiswa perantau Bugis-Makassar di Melbourne, Australia. Jurnal Pendidikan dan Kebudayaan, 19(2), 252-267.

Sonn, C., Bishop, B., \& Humphries, R. (2000). Encounters with the dominant culture: Voices of indigenous students in mainstream higher education. Australian Psychologist, 35(2), 128-135. https://doi.org/10.1080/00050060008260334

Spitzberg, B. H., \& Changnon, G. (2009). Conceptualizing intercultural competence. In D. K. Deardorff (Ed.), The SAGE handbook of intercultural competence. SAGE Publications, Inc.

Stanciu, A., \& Vauclair, C.-M. (2018). Stereotype accommodation: A socio-cognitive perspective on migrants' cultural adaptation. Journal of Cross-Cultural Psychology, 49(7), 1027-1047. https://doi.org/10.1177/0022022118777300

Steele, C. M. (1997). A threat in the air: How stereotypes shape intellectual identity and performance. American Psychologist, 52(6), 613-629. https://doi.org/10.1037/0003066X.52.6.613

Tohidian, N. B., \& Quek, K. M.-T. (2017). Processes that inform multicultural supervision: A qualitative meta-analysis. Journal of Marital and Family Therapy, 43(4), 573-590. https://doi.org/10.1111/jmft.12219

Walton, G. M., \& Spencer, S. J. (2009). Latent ability:Grades and test scores systematically underestimate the intellectual ability of negatively stereotyped students. 
Psychological Science, 20(9), 1132-1139. https://doi.org/10.1111/j.14679280.2009.02417.x

Wang, K. T., Heppner, P. P., Fu, C.-C., Zhao, R., Li, F., \& Chuang, C.-C. (2012). Profiles of acculturative adjustment patterns among Chinese international students. Journal of Counseling Psychology, 59(3), 424-436. https://doi.org/10.1037/a0028532

Ward, C., Bochner, S., \& Furnham, A. (2001). The psychology of culture shock. Routledge.

Ward, C., \& Geeraert, N. (2016). Advancing acculturation theory and research: The acculturation process in its ecological context. Current Opinion in Psychology, 8, 98104. https://doi.org/https://doi.org/10.1016/j.copsyc.2015.09.021

Ward, C., \& Kennedy, A. (1993). Where's the "culture" in cross-cultural transition?: Comparative studies of sojourner adjustment. Journal of Cross-Cultural Psychology, 24(2), 221-249. https://doi.org/10.1177/0022022193242006

Ward, C., \& Kennedy, A. (1999). The measurement of sociocultural adaptation. International Journal of Intercultural Relations, 23(4), 659-677. https://doi.org/10.1016/S0147-1767(99)00014-0

Wijanarko, E., \& Syafiq, M. (2013). Studi fenomenologi pengalaman penyesuaian diri mahasiswa Papua di Surabaya. Jurnal Psikologi Teori \& Terapan, 3(2), 79-92.

Wilson, J., Ward, C., Fetvadjiev, V. H., \& Bethel, A. (2017). Measuring cultural competencies: The development and validation of a revised measure of sociocultural adaptation. Journal of Cross-Cultural Psychology, 48(10), 1475-1506. https://doi.org/10.1177/0022022117732721

Yang, P. (2018). Developing TESOL teacher intercultural identity: An intercultural communication competence approach. TESOL Journal, 9(3), 525-541. https://doi.org/10.1002/tesj.356

Yuniarti, K. W. (2010). Discovering variables of acculturation for sojourners: An explorative study of Indonesian students living in Germany. Anima, Indonesian Psychological Journal, 25(2), 81-93. 